OXCHECK is funded primarily by the Imperial Cancer Research Fund.

1 Working Group of the Coronary Prevention Group and the British Heart Foundation. An action plan for preventing coronary heart disease in primary care. BMF 1991;303:748-50.

2 Tunstall-Pedoe $H$. The Dundee coronary risk-disk for management of change in risk factors. BMF 1991:303:744-7.

3 Imperial Cancer Research Fund OXCHECK Study Group. Prevalence of risk factors for heart disease in OXCHECK trial: implications for screening in primary care. $B M \mathcal{F}$ 1991;302:1057-60.
+ CIA [compurer program] London: BMJ, 1989.

Scientific Committee of the Simon Broom Register Group. Risk of tat coronary heart disease in familial hvpercholesterolaemia. B.11 1991:303 $893-6$

6 World Health Organisation European Collaborative Group. Multifactorial tria in the prevention of coronary heart disease. 1 . Recruitment and initia findings. Eur Heart $\mathcal{f}$ 1980:1:73-80

7 Mann J, Lewis B, Shepherd J, Winder A, Fenster S, Rose L, et al. Blood lipid concentrations and other cardiovascular risk factors: distribution, prevalence, and detection in Britain. BMF 1988;296:1702-5.

Accepted I fuly 1992

\title{
Value of the Dundee coronary risk-disk: a defence
}

\author{
Hugh Tunstall-Pedoe
}

We invited Professor Tunstall-Pedoe, who is a member of the Coronary Prevention Group and originator of the Dundee coronary risk-disk, to comment on the results of the $O x$ ford computer simulation.

\section{Cardiovascular \\ Epidemiology Unit,} Ninewells Hospital and Medical School, Dundee DD1 9SY

Hugh Tunstall-Pedoe, director

BMF 1992;305:231-2
We launched the "Action Plan" and Dundee coronary risk-disk ${ }^{2}$ in September 1991. So far 3500 disks have been purchased. We recently surveyed users, and their opinions, from clinical practice, contrast with the judgments from Randall et al's modelling exercise.

The action plan and risk-disk were designed not just to categorise risk but to motivate change and monitor progress. The Dundee rank places patients from the front (one) to the back (100) of a metaphorical bus queue for a heart attack. ${ }^{2}$ The ranking is based on the Dundee score, which combines smoking, blood pressure, and serum cholesterol concentration, and on the distribution of that score in a large random population survey, the Scottish heart health study. ${ }^{3}$

The Dundee rank has been welcomed because the bus queue metaphor and 1-100 frame of reference are understood. In rejecting the Dundee rank in favour of the Dundee score Randall et al have been precipitate. They are at odds with most users, and rewriting of the action plan using the Dundee score may cause unnecessary difficulty for readers. They are not only throwing out the baby with the bath water but are also going to miss the bus.

\section{User survey}

The British Heart Foundation sent a questionnaire to 296 randomly selected purchasers of the Dundee coronary risk-disk. We have had 187 respondents, 156 of whom had used the disk on some 10000 patients but with great variation. The 31 others had not opened the packet; had not learnt to use it; had experienced difficulties (lessened in those watching the instructional video); or had not bought the disk for themselves. Many responses were incomplete, but questions relevant to Randall et al's paper follow.

Asked about use of a protocol, 28 did not answer, 70 used no protocol, 52 used a practice protocol, and six used the Coronary Prevention Group and British Heart Foundation action plan' (which might have influenced some of the other protocols). Twenty two respondents did not state whether they showed the risk calculations to patients, but 74 always did, and 49 sometimes did; only 11 never did. Twenty seven did not state a preference for the Dundee rank or score, but 57 preferred the rank, 31 preferred the score, and 41 used both equally. Twenty five did not state whether they thought that the disk motivated patients, 130 thought that it did (57 answered an unqualified yes and 73 answered sometimes), and only one respondent thought it did not. Asked whether they would recommend the Dundee coronary risk-disk to others, nine did not answer, six ticked no, and 141 ticked yes (49 without reservation and 92 with qualification). Sixty two respondents said they would attend user meetings. Most responses were confined to the codings, but additional comments were received from 52 , explaining non-use (as above) or enthusiasm (see box).

\section{Users' comments on Dundee coronary risk-disk}

Family doctor (used on 100 patients): This is an excellent development. The ability to numerically tell patients how much they can achieve by changing their risk parameters is very motivating.

Practice nurse (50 patients): The risk-disk has been very useful for assessment and made my job more interesting and the patients do seem interested also.

Occupational physician (500 patients): It works well. It motivates patients by figures they can understand and not by rhetoric from the doctors.

Family doctor (200 patients): I find the disk excellent. Multifactorial risk assessment remains hopelessly vague without some form of complicated calculation which the disk performs so easily. Most patients understand and appreciate the "queuing for a coronary" analogy and undoubtedly the feedback they obtain about moving down the queue following lifestyle change reinforces motivation. I am often surprised at the rank result compared with my own subjective risk assessment and this saves me considerable time by avoiding excessive effort in low risk people. I know four recidivist smokers who have given up (for 2-8 months so far) once they found they were at the front of the queue.

\section{OXCHECK and Scottish data}

Randall $e t$ al rejected the Dundee rank because of the unexplained difference in distributions of risk score in OXCHECK and the Scottish heart health study. ${ }^{3}$ Practice populations may differ because smoking varies by social class, and there are potential biases in other factors. This does not invalidate the Dundee rank as an external, population based frame of reference. The action plan suggested that each practice adjusts its cut off points from experience in its own population.' Relative rankings are unaffected by adjusting the scale.

Randall et al imply that because the OXCHECK and Scottish data disagree, the Scottish data are misleading. However, 10000 Scottish men and women were studied from 260 practices in 22 districts across Scotland by using international standardisation and quality control, and the results are published. ${ }^{3}$ The OXCHECK data come from 5000 patients in five clustered practices in one corner of southern England and their full risk factor data are not published. ${ }^{+}$The large and puzzling deviation between the OXCHECK and Scottish studies cannot be explained until the OXCHECK data are released; meanwhile there is no inherent reason to consider OXCHECK cut off points a better guide for British doctors than the Scottish study and the Dundee rank. Recent British surveys show insignificant differences in risk factors between Scotland and England." 


\section{Risk factor weightings}

Randall et al suggest that an error may arise through using weightings derived from men seen 18-20 years ago. The Dundee score is based on data of similar age to that of almost all other British ${ }^{7}$ and American scoring systems." "Risk assessment must be based on historical comparison (unless it is spurious), and for that reason it will take a similar length of time to know whether the error actually exists.

\section{Unifactorial versus multifactorial assessment}

The Dundee score will not categorise everybody with one risk factor as being at high risk, and Randall et al imply that individual risk factors should be considered in isolation. That idea is outmoded. For every person identified by exceptional levels of one risk factor there are many more with moderately raised levels of two or more factors who are at the same or greater risk because risk factors interact multiplicatively. ${ }^{211}$

Cigarette smoking is equivalent to adding 20 $40 \mathrm{~mm} \mathrm{Hg}$ on to diastolic blood pressure or $1-3 \mathrm{mmol} / \mathrm{l}$ on to serum cholesterol concentration. These concepts can be shown on the Dundee risk-disk, but what they imply is that the multifactorial approach is not a second best approach to save work but the only valid one for managing cardiovascular risk factors.

After three decades of obsession with one dimensional algorithms for diastolic blood pressure, doctors have finally got the multifactorial message. ${ }^{22}$ Lipidologists are belatedly beginning to do so. You cannot treat one risk factor and take account of the others without a valid scoring system which takes account of their interaction.

The established protocols for unifactorial risk assessment and modification are too naive. Simplistic, one dimensional, black and white algorithms must now incorporate the three dimensional solid state, and full colour, of multifactorial management.

\section{Conclusion}

The action plan and Dundee coronary risk-disk are a multifactorial approach to cardiovascular risk factor management. They form a necessary progression from the unifactorial approach and reflect the epidemiological evidence, cost effectiveness, and the latest clinical teaching. A change from tradition is required and this will not suit everybody, but many users welcome the interactive approach and the apparent motivating effect of the Dundee rank. So far the disk seems more popular than the action plan. Many practices are using it without a formal protocol. There is a perceived need for educational exchange. The OXCHECK analysis is of value, but its deviations from the Scottish study, which included 50 times as many practices, are unexplained.

The opinions expressed are those of the author and not the Scottish Office Home and Health Department, which funded much of the research.

1 Working Group of the Coronary Prevention Group and the British Hear Foundation. An action plan for preventing coronary heart disease in primary care. BMF 1991;303:748-50

Tunstall-Pedoc $\mathrm{H}$. The Dundec coronary risk-disk for management of chang in risk factors. BMJ 1991;303:744-7.

3 Smith WCS, Tunstall-Pedoc $H$, Crombic IK, Tavendale R. Concomitants of excess coronary deaths-major risk factor and lifestyle findings from 10359 men and women in the Scottish Heart Health Study. Siot Med y 1989;34:550-5

4 Imperial Cancer Research Fund OXCHECK Study Group. Prevalence of risk factors for heart disease in OXCHECK trial: implications for screening in primary care. BMJ 1991;302:1057-60.

5 Office of Population Censuses and Survers. The dietury and nutritional sure of British adults. London: HMSO, 1990.

6 Cox BD, Blaxter M, Buckle ALJ, Fenner NP, Golding JF, Gore M, et al. The health and lifestyle survey. London: Health Promotion Research Trust, 1987.

7 Jarrett RJ, Shipley MJ, Rose G. Weight and mortality in the Whitchall study. BM7 1982:285:535-7.

8 Shaper AGi, Procock SJ, Phillips AN, Walker M. A scoring system to identify men at high risk of a heart attack. Heulth Trends 1987;19:37-9.

9 Wilson PWF, Castelli WP, Kannel WB. Coronary risk prediction in aduls (the Framingham study). Am f (Cardiol 1987;59:91-4G.

10 Kannel WB, Neaton JD, Wentworth D, Thomas HE, Stamler J, Huller SB et al. Overall and coronary heart discase mortality rates in relation to major risk factors in 325,348 men screened for the MRFIT. Am Heurl $\%$ 1986;112:825-36

11 Tunstall-Pedoc H. Who is for cholesterol testing? BM7 1989;298:1593-4.

12 Poulter N. Management of multiple risk factors for coronary heart discase in patients with hypertension. Am Heurt 7 1991:121 (suppl II) 246-50.

\title{
Partners in Practice
}

\section{The primary health care team: history and contractual farces}

\author{
John Hasler
}

This is the first of a series of articles focusing on the current tasks and functions of the primary health care team

\section{Medical School Offices, John Radcliffe Hospital, Oxford OX3 9DU John Hasler, regional postgraduate adviser and clinical lecturer in general practice}

BMf 1992;305:232-4
It is not possible to state precisely when the concept of a team in primary health care became a reality. As with so many developments its progress was slow and its start unrecognisable. Before the arrival of the NHS in 1948 most general practitioners were in single handed practice, often with their wives as their only supportreceptionists as such were uncommon. There were no attachments of district nurses and most doctors practised from their own houses.' While there had been occasional ideas about a more progressive approach to primary medical care, these had been sporadic and had had little general effect. General practitioners saw their role as reactive and their potential role in prevention of disease had not yet dawned on most of them.

In this article I examine subsequent developments in three phases: from the inception of the NHS to the doctors' charter in 1966, from then to the new contract in 1990 , and the present.

The '50s were difficult times for general practice. Removed from the hospital service and operating in a financial arrangement where any money spent on staff or premises directly reduced their income, many general practitioners looked with some envy on their specialist colleagues as the hospital service and technological advances took shape. But the frustrations had their positive effects, the most notable of which was formation of the College of General Practitioners, which attracted some of the ablest minds of the day. Some of these people turned their thoughts to starting primary care teams. As money was scarce, buildings often inadequate, and the potential of nursing work in general practice largely unrecognised, the theme at this stage largely concerned the attachment of district nurses and health visitors.

\section{ATTACHMENT OF NURSING STAFF}

The first reports of attachment of local authority nursing staff, who were then working in geographical areas under the control of the medical officers of health, appeared in the ' $50 \mathrm{~s}$ and early ' $60 \mathrm{~s}^{.2}$ 'But it was not all plain sailing. It took men of vision to see the possibilities, and Ian McDougall, county medical officer of health for Hampshire, a stalwart enthusiast for attachment schemes, once recalled how he had been 